\title{
Study on Flipped Classroom Applied in Economy and Management Courses in Higher Vocational Education
}

\author{
Xiaojing Dong \\ Xijing University, Xi'an, Shanxi, China \\ 664186437@qq.com
}

\begin{abstract}
Keywords: Flipped Classroom, Teaching Mode Reform, Higher Vocational Education
\end{abstract}
\begin{abstract}
Higher Vocational Education is named as higher vocational skills education. Its essence is social vocation, higher vocational students will be able to successfully engage in different and many kinds of vocations, after they learn their courses.How to cultivate higher educational students high-quality professional skills with innovation ability. With the reformation of our country and the changeable world,these students majoring in Economy and Management, could get much information and need the combination of theory and practice.The paper gets a result that flipped classroom is a key and nice teaching mode, because it makes students progress in studying and applying.
\end{abstract}

\section{The definition of higher vocational education}

Higher Vocational Education is namely higher vocational skills education. Its essence is social vocation, higher vocational students will be able to successfully engage in different and many kinds of vocations, after they learn their courses.Modern higher vocational education serves students for vocations as the guidance. The teachers provide studying service for the purpose of higher vocational education mode to meet the needs of society,the students and the enterprises.

However, there are many problems in the construction of education curriculum system and teaching implementation in the existing higher vocational courses, mainly in the following aspects.

\section{The situation of current traditional teaching mode in economy and management courses 2.1 The teaching style is traditional, rigid and monotonous}

The teaching form is still based on the traditional classroom teaching. Classrooms is the center, teachers are the main body and the teaching material are the core. The teaching procedure is according to teachers' explanation, at the same time, student listens to the record.[1] Teacher demonstrate passages, figures and charts and student write them. Listening, discussing, reading, memorizing, understanding, and writing exercises are the main ways for students to learn courses.

\subsection{Practice teaching and professional work is divided}

Students begin in practice after studying the theory. The curriculum is still organized according to the logic structure of the subject and lacks organic integration. The courses arrangement is still from the foundation to the major, from theory to application. The content of the course is mainly declarative knowledge theory, and still is according to the inherent logic of knowledge organization. Practicality is not strong enough.

\subsection{Lack of learning situation}

All of Economy and Management courses are sitting lessons. Students learn the theories and results in class, which are not in practice. After the training of professional practice, students are not familiar with the field of professional work, lack of professional awareness and unclear learning purpose, which is difficult to mobilize the enthusiasm and initiative of students. Students study the application of theory of knowledge, because of the lack of practical experience and lack of learning situation by building job situation.So students majoring in Economy and Management often feel empty, abstractand and boring. Abstruse theoretical knowledge is difficult to be graspped and thus not 
interested by students. So high-quality professional education must be innovated at once.

\section{Analyse the flipped classroom (FC) in economy and management courses 3.1 The origin and development of flipped classroom}

At first, the flipped classroom instruction was applied in America by Jonathan Bergmann and Aaron Sams, who were two teachers in High School. They just recorded the Power - Point presentation broadcast and explain, and upload video to the Internet, to help the class students on leave. But they quickly realized that this video teaching method could be beneficial to all students.[2]

Then, in 2011, a new type of teaching structure education, introduce the concept of flipped classroom.From then on, the new teaching form began to be known by many teachers. It turns the traditional classroom teaching mode. Students in the class through information technology assistance to complete the teaching video to watch and learn, learning resources, including classroom time collaboration is mainly completed by teachers and students together to explore and interactive communication activities .

\subsection{The characteristics of flipped classroom}

a. For the advanced information technology support to flip the realization of the classroom, teachers need to advance the teaching courseware and uploaded to the Internet after processing, the students with the help of advanced information technology, can make use of the Internet before class to obtain the high quality teaching resources to complete the knowledge transfer process, and to make the classroom interaction between teachers and students.[3]This teaching mode is based on the popularization of Internet and computer technology is widely used in the field of education, on the basis of it to reduce the effect of objective conditions on learners' learning effectiveness, broke the traditional teaching methods to study the limit of time and space, can learn all the valuable data are provided to learners at any time and place, make education to an open environment full of information flows.

b. Take the student as the center, fully mobilize students cooperation between flip built the student active learning the classroom learning environment, teaching courseware after permanent learning content, students can freely according to their own actual situation to arrange learning time and learning place, the learning process can be arranged in a relaxed atmosphere, don't have to worry about the class because their distraction or illness, to participate in extracurricular activities such as reasons to miss the content of the teacher, and in the process of watching the teaching courseware.It is always possible to repeat the teaching contents or adjust the teaching rhythm according to the degree of acceptance of the teaching content. Were perplexed by his place to write down, together with the classmates and teachers to the class discussion, this way to make the students passively listening to the teacher from the need in the traditional classroom lectures of the receiver, can turn into the initiative to ask questions and the researchers to solve the problem together with the others. Students can get individual guidance from teachers when necessary, and truly achieve personalized education. Turn at the same time, the classroom is also a kind of need highly involved in the classroom, students through classroom activities for students more time, so that the students can be repeatedly discussion, in view of the learning content to extend and deepen the understanding of knowledge and understanding of the purpose. Flip the classroom can increase students' interactive cooperation, lets the student in the cooperative learning task, students can through collaborative learning in teams to help each other, learn from each other and learn from each other, develop their spirit of mutual cooperation.

\section{The advantage of Flipped Classroom}

\subsection{Increasing interaction between teachers and students}

Traditional class is taught by teachers teaching content, students can choose according to their interests and habits of their favorite teaching methods and contents, teachers are hard to change their teaching habits to meet all of the students, the traditional teaching method is easy to cause the teacher 
teaching and student learning do not match, the attraction of classroom for students to reduce , eventually lead to students' learning effect is not ideal. In turn the classroom, the students can according to their own habits by watching before the class teaching courseware in the form of a complete knowledge of the teaching process, in the classroom, teachers will have more time to participate in student's study group discussion, according to the specific situation to understand and answer the problems encountered in the learning process of students, when necessary to meet the same problem students organizations together to set up counseling group or small the lecture. By using flipped classroom, the role of teachers is transformed from the traditional knowledge imparting to the facilitator and mentor of learning.

\subsection{Teaching model design}

Flipped classroom enhances the teaching effect by reversing the knowledge transfer and internalization process of the traditional classroom. American professor Robert Tall - Bert after years of accumulation of teaching, summarizes flip the implementation of the class structure model, the model describes briefly turn classroom implementation of the important link in the process of (as shown in figure 1)[4].

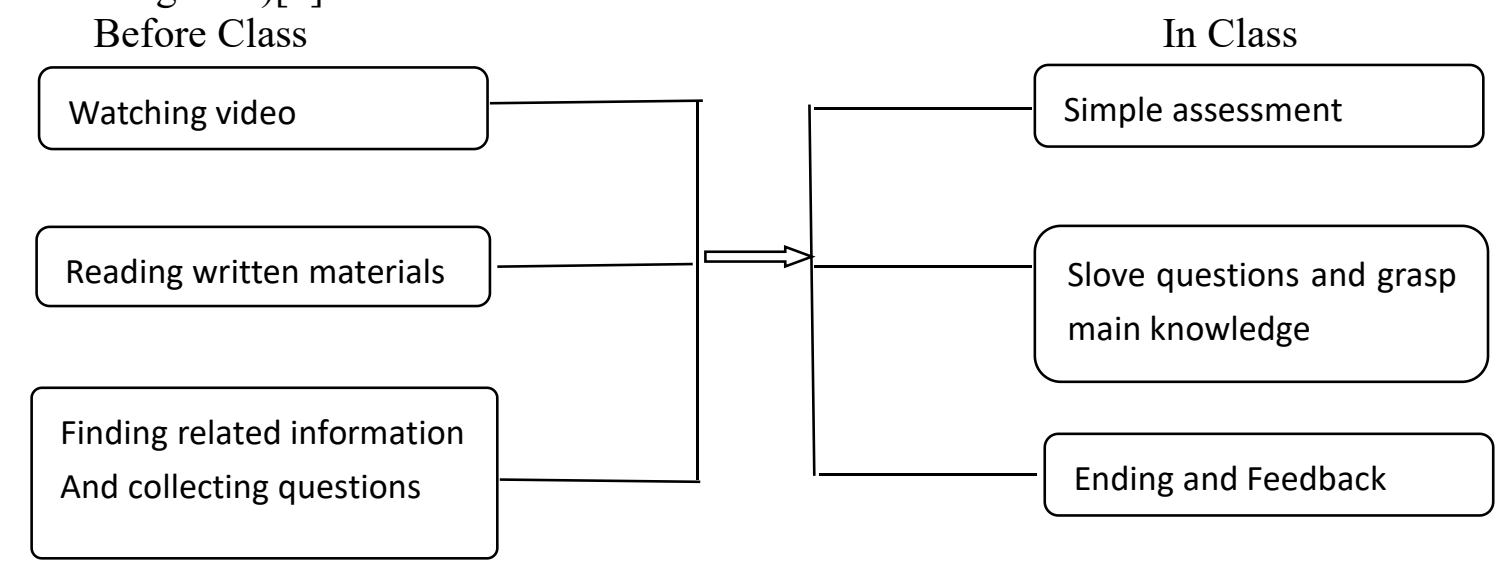

Figure 1 Flipped Classroom structure

\subsubsection{Teacher teaching process design}

In the traditional teaching mode, teachers can teach theoretical knowledge in the classroom, and teachers can establish a theme for each class, and then prepare the teaching content around the topic. [5]. Class is mainly the students listen to the teacher tells the way, teachers can completely control the teaching rhythm and teaching contents, but this kind of teaching method does not take into account the students' individual needs, it is difficult to arouse the students' interest in learning,And it's very easy to get the content out of production. In the project-type teaching of flipped classroom, students learn the theoretical knowledge required by teaching courseware before class, and the class time is mainly for students to finish the project tasks themselves. The time distribution in class and the depth of discussion on teaching content cannot be completely controlled by teachers. In class, teachers and students need to interact with each other. Teachers need to deal with all kinds of questions raised by students.

\subsubsection{Design of student learning process}

(1) preparation stage before class.

Integrating the project-type teaching of flipped classroom requires students to take proactive measures before class and actively devote themselves to the learning of new knowledge. Due to teachers' teaching courseware has covered all the knowledge involved in the teaching project, students can on the project first before learning courseware are listed in the learning task and learning content analysis, the basis of according to oneself and interest selectively watch courseware content.

If students have an unintelligible problem by looking up information and viewing courseware, they 
can record the problem and discuss it with their classmates or teachers in class. This approach enables students with different bases to follow their own basic knowledge.

Taking the situation and accepting the teaching project to choose the content and speed of the teaching courseware to further improve the learning efficiency,

Pre-class preparation stage is the cornerstone of the whole flipped classroom teaching.

(2) understand the application stage.

Preparation for students before the class through personalized learning method to master the teaching project contains conceptual knowledge, and the work process of involving had certain understanding, understanding of knowledge into the class application stage. Project teaching method in every teaching project contains certain tasks, a member of the team can be composed of several students, prior to the start of the project need a division of tasks for each team members. Project after the start of class students will need to rely on the understanding of knowledge points and teaching material in the description of the project themselves to complete their tasks, in the process of completing the task at any time to record their work steps, each step of knowledge points, the working process encountered problems and solutions. Everyone participates in project practice to complete the understanding of theoretical knowledge from abstract to concrete transformation process, and complete the process of translating complex operation process into concrete work practice in teaching courseware.

(3) the stage of knowledge internalization.

The students' understanding of some problems during the pre-class preparation period may only be on the surface, but it does not fully understand its connotation. Through hands-on participation in the completion process of teaching projects in class, we can deeply contact each link in the work process and learn how to apply theory to practice.Through discuss with classmates, talk things over solve problems encountered in the process of work, can make the students find a lot of preparation before the class didn't pay attention to the detail process of operation, expansion of breadth and depth of knowledge.

\section{Conclusion}

In the traditional teaching mode, it is difficult to arouse the students' interest in learning,And it's very easy to get the content out of production. But in the flipped class, the design of class is very effect in practising. We can deeply contact each link in the work process and learn how to apply theory to practice.It is good for college students from Economy and Management Department.

\section{Acknowledgement}

It is from the item How to make students progress in Economy and Management courses, which is a task from Xijing University(Xijing University support GZJGGH1703).

\section{References}

[1] Burden,P.(1982) .Implications of teacher career develop-ment: New roles for teachers , administrators and professors[J].Actionin Teacher Education, 4( 4):21 - 25.

[2] Crouch,H.Mazur,E.(2001).Peer instruction: Ten years of experience and results[J].American journal of physics, 69(9): $970-977$.

[3] Inverting the Linear Algebra Classroom. Robert Talbert.

http://prezi.com/dzorbkpy6tam/ inverting-thelinear-algebra-classroom.

[4] Assessing students' changing perceptions of higher education:research in higher education,Bitzer,E.M.[J].South African Journal of Higher Education, 2003, Vol.17 (3), pp. 164-177.

[5] Learning in academia is more than academic learning: action research in academic practice for and with medicalacademics, Chris Trevitt[J]. Educational Action Research, 2008,Vol.16(4), pp.495-515. 